\title{
Advanced Stirling Convertor Dynamic Test Approach and Results
}

David W. Meer

Sest, Inc., Middleburg Heights, Ohio

Dennis Hill

Lockheed Martin Space Systems Company, King of Prussia, Pennsylvania

Joseph J. Ursic

Analex Corporation, Cleveland, Ohio 


\section{NASA STI Program . . . in Profile}

Since its founding, NASA has been dedicated to the advancement of aeronautics and space science. The NASA Scientific and Technical Information (STI) program plays a key part in helping NASA maintain this important role.

The NASA STI Program operates under the auspices of the Agency Chief Information Officer. It collects, organizes, provides for archiving, and disseminates NASA's STI. The NASA STI program provides access to the NASA Aeronautics and Space Database and its public interface, the NASA Technical Reports Server, thus providing one of the largest collections of aeronautical and space science STI in the world. Results are published in both non-NASA channels and by NASA in the NASA STI Report Series, which includes the following report types:

- TECHNICAL PUBLICATION. Reports of completed research or a major significant phase of research that present the results of NASA programs and include extensive data or theoretical analysis. Includes compilations of significant scientific and technical data and information deemed to be of continuing reference value. NASA counterpart of peer-reviewed formal professional papers but has less stringent limitations on manuscript length and extent of graphic presentations.

- TECHNICAL MEMORANDUM. Scientific and technical findings that are preliminary or of specialized interest, e.g., quick release reports, working papers, and bibliographies that contain minimal annotation. Does not contain extensive analysis.

- CONTRACTOR REPORT. Scientific and technical findings by NASA-sponsored contractors and grantees.
- CONFERENCE PUBLICATION. Collected papers from scientific and technical conferences, symposia, seminars, or other meetings sponsored or cosponsored by NASA.

- SPECIAL PUBLICATION. Scientific, technical, or historical information from NASA programs, projects, and missions, often concerned with subjects having substantial public interest.

- TECHNICAL TRANSLATION. Englishlanguage translations of foreign scientific and technical material pertinent to NASA's mission.

Specialized services also include creating custom thesauri, building customized databases, organizing and publishing research results.

For more information about the NASA STI program, see the following:

- Access the NASA STI program home page at http://www.sti.nasa.gov

- E-mail your question via the Internet to help@ sti.nasa.gov

- Fax your question to the NASA STI Help Desk at $443-757-5803$

- Telephone the NASA STI Help Desk at 443-757-5802

- Write to: NASA Center for AeroSpace Information (CASI) 7115 Standard Drive Hanover, MD 21076-1320 


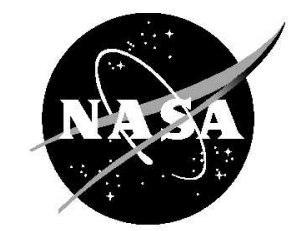

\section{Advanced Stirling Convertor Dynamic Test Approach and Results}

David W. Meer

Sest, Inc., Middleburg Heights, Ohio

Dennis Hill

Lockheed Martin Space Systems Company, King of Prussia, Pennsylvania

Joseph J. Ursic

Analex Corporation, Cleveland, Ohio

Prepared for the

Seventh International Energy Conversion Engineering Conference (IECEC)

sponsored by the American Institute of Aeronautics and Astronautics

Denver, Colorado, August 2-5, 2009

Prepared under Contract NNC09JF24T

National Aeronautics and

Space Administration

Glenn Research Center

Cleveland, Ohio 44135 


\section{Acknowledgments}

This work is funded through the National Aeronautics and Space Administration (NASA) Science Mission Directorate.

The authors thank Scott Cutlip of NASA Glenn Research Center (GRC) for his help in designing the test fixture and Jim Szelagowski of NASA Glenn for his help in running the vibrational tests and providing the raw data.

The authors also thank Jack Chan from Lockheed Martin (LM), Rebecca Richardson from

Department of Energy (DOE), and Ed Lewandowski, Jeff Schreiber, and Richard Shaltens of NASA Glenn for their helpful comments in reviewing this paper.

Level of Review: This material has been technically reviewed by NASA technical management.

Available from

NASA Center for Aerospace Information

7115 Standard Drive

Hanover, MD 21076-1320
National Technical Information Service 5301 Shawnee Road Alexandria, VA 22312

Available electronically at http://gltrs.grc.nasa.gov 


\title{
Advanced Stirling Convertor Dynamic Test Approach and Results
}

\author{
David W. Meer \\ Sest, Inc. \\ Middleburg Heights, Ohio 44130 \\ Dennis Hill \\ Lockheed Martin Space Systems Company \\ King of Prussia, Pennsylvania 19406 \\ Joseph J. Ursic \\ Analex Corporation \\ Cleveland, Ohio 44135
}

\begin{abstract}
The U.S. Department of Energy (DOE), Lockheed Martin Corporation (LM), and NASA Glenn Research Center (GRC) have been developing the Advanced Stirling Radioisotope Generator (ASRG) for use as a power system for space science missions. As part of the extended operation testing of this power system, the Advanced Stirling Convertors (ASC) at NASA GRC undergo a vibration test sequence intended to simulate the vibration history that an ASC would experience when used in an ASRG for a space mission. This sequence includes testing at workmanship and flight acceptance levels interspersed with periods of extended operation to simulate prefueling and post fueling. The final step in the test sequence utilizes additional testing at flight acceptance levels to simulate launch. To better replicate the acceleration profile seen by an ASC incorporated into an ASRG, the input spectra used in testing the convertors was modified based on dynamic testing of the ASRG Engineering Unit (ASRG EU) at LM. This paper outlines the overall test approach, summarizes the test results from the ASRG EU, describes the incorporation of those results into the test approach, and presents the results of applying the test approach to the ASC-1 \#3 and \#4 convertors. The test results include data from several accelerometers mounted on the convertors as well as the piston position and output power variables.
\end{abstract}

\section{Introduction}

The Department of Energy (DOE) plans to develop the Advanced Stirling Radioisotope Generator (ASRG) for the National Aeronautics and Space Administration (NASA) for use on future science missions, such as Mars rovers, and deep space missions. Lockheed Martin Corporation (LM) Energy Systems of Valley Forge, Pennsylvania, serves as the system integrator under contract to DOE. Sunpower, Inc. of Athens, Ohio is developing the Advanced Stirling Convertor (ASC) for the ASRG under a NASA Research Announcement award with NASA Glenn Research Center (GRC) of Cleveland, Ohio. GRC also provides technology development for the ASC. The ASRG provides substantial efficiency and specific power improvements over radioisotope power systems utilizing heritage designs.

Figure 1 depicts the ASRG Engineering Unit (ASRG EU) with part of the outer housing removed to show the internal components. This non-nuclear generator replaces the General Purpose Heat Source (GPHS) modules with electrically powered heat sources to validate the generator's performance. LM assembled the ASRG EU in 2007 and performed system level testing on the unit in 2008. The current ASRG EU uses two Sunpower-designed ASCs inside a beryllium enclosure that acts as structure, radiator, and micrometeoroid shield. The generator housing also supports the two convertors, which a controller synchronizes to minimize the forces generated by the motion of the convertor components. 


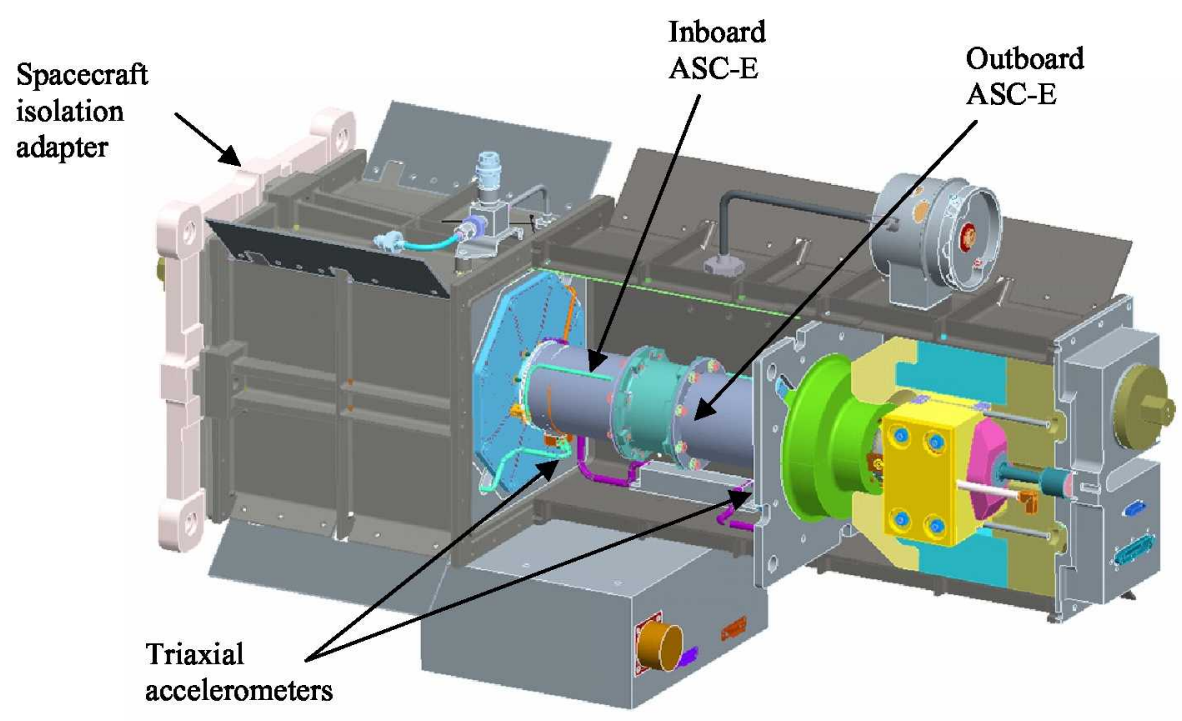

Figure 1.-Advanced Stirling Radioisotope Generator Engineering Unit cutaway view.

The GRC contribution to the development of the ASC comes in project management and supporting technology, including tasks in reliability, high-temperature materials, structures, advanced analysis, organics, permanent magnets, and convertor testing. Extended operation testing represents a critical component for developing long-life radioisotope power systems, suited for long duration missions of up to 14 years. While accelerated life testing techniques can be applied to some components, they cannot be applied to a continuously operating system like the ASRG. Ideally, this extended life testing should expose the convertors to conditions that duplicate those a flight convertor would see during its life. This paper details the effort to replicate one aspect of the operational conditions that a flight ASC would experience, exposure to vibration during post-assembly testing and launch.

The GRC has been involved with past work on vibrational testing of Stirling convertors. Previous work included dynamic testing of an operating Stirling Technology Demonstration Convertors (TDC) to levels required for vibration qualification and vibration modal characterization using base shake input. Most recently, work on the 110-Watt Stirling Radioisotope Generator (SRG110) developed a dynamic model of the generator under vibration, used this model to recommend several improvements to the SRG1 10 configuration and mounting, and validated the model with experimental results. This paper presents the overall vibration test approach implemented at GRC for all ASC units, provides vibrational spectra based on the dynamic testing of the ASRG EU, and details the results of the first attempt to utilize this data in the vibrational testing of an ASC.

\section{Nomenclature}

$\begin{array}{ll}\text { ASC } & \text { Advanced Stirling Convertor } \\ \text { ASRG } & \text { Advanced Stirling Radioisotope Generator } \\ \text { CSAF } & \text { Cold Side Adapter Flange } \\ \text { DOE } & \text { Department of Energy } \\ \text { EU } & \text { Engineering Unit } \\ \text { FLDT } & \text { Fast Linear Displacement Transducer } \\ \text { GRC } & \text { Glenn Research Center } \\ \text { LM } & \text { Lockheed Martin Corporation } \\ \text { NASA } & \text { National Aeronautics and Space Administration } \\ \text { RMS } & \text { Root Mean Square } \\ \text { RPS } & \text { Radioisotope Power Source }\end{array}$


SDL Structural Dynamics Laboratory

SRG110 110 Watt Stirling Radioisotope Generator

TDC Technology Demonstration Convertor

\section{Extended Life Vibration Test Plan}

As noted in the introduction, one of the goals of the extended life testing program at NASA GRC entails replicating the life cycle of a convertor used for a flight mission while maximizing extended operation time. In general, the sequence followed after fabrication includes workmanship testing, assembly into the generator, fueling, a short operation period to verify full functionality, flight acceptance testing, storage for periods up to 3 years, launch, and operation for periods up to 14 years. To reproduce this operational sequence as closely as possible, convertors in the extended life testing program at GRC first undergo a workmanship vibration test as part of the fabrication process. After receipt by GRC, the convertors then operate for between 5,000 and $10,000 \mathrm{hr}$ to simulate the storage period. After removing the convertor from the extended operation testing facility in the Stirling Research Laboratory, the convertor is transferred to the Structural Dynamics Laboratory (SDL) for additional vibration exposure. In order to maximize the extended operation time for the convertors and minimize the work required to relocate convertors between facilities, the flight acceptance and launch simulation dynamic tests occur during the same session. The launch simulation test utilizes the same vibration levels as the flight acceptance test, but adds an additional minute at those levels to simulate vibration during launch. Table 1 summarizes the typical test sequence for a typical axis of the convertor, in this case, the $\mathrm{Z}$ axis, one of the two lateral axes. Sine sweeps to verify the health of the convertor bracket the two identical tests, run for $1 \mathrm{~min}$ each, at launch acceptance levels. When fully implemented, the acceleration spectra are shaped based on the results of the vibration testing of the ASRG EU. The next section of the paper details the process used to test and validate the input shaping.

TABLE 1.-TYPICAL SINGLE AXIS VIBRATION TEST SEQUENCE

\begin{tabular}{|c|l|l|}
\hline Axis & \multicolumn{1}{|c|}{ Test title } & \multicolumn{1}{c|}{ Test description } \\
\hline$Z$ & Pre-test sine sweep & $0.125 \mathrm{~g}$ Sine sweep, 5 to $2000 \mathrm{~Hz}, 2$ Oct/min, weep up and down \\
\hline$Z$ & Flight acceptance & 8.9 grms Flight level acceptance random 20 to $2000 \mathrm{~Hz}, 60 \mathrm{sec}$ \\
\hline $\mathrm{Z}$ & Launch simulation & 8.9 grms Launch simulation random 20 to $2000 \mathrm{~Hz}, 60 \mathrm{sec}$ \\
\hline $\mathrm{Z}$ & Post-test sine sweep & $0.125 \mathrm{~g}$ Sine sweep, 5 to $2000 \mathrm{~Hz}, 2 \mathrm{Oct} / \mathrm{min}$, sweep up and down \\
\hline
\end{tabular}

\section{ASRG EU Dynamic Test Results}

During testing of the ASRG EU at LM's facility in Valley Forge, Pennsylvania in May and June of 2008, the full generator unit was tested on a shaker table to qualification levels. Figure 2 depicts the ASRG EU mounted on the shaker table in preparation for one of the lateral axes tests. Instrumentation included a triaxial accelerometer mounted on each of the pressure vessels of the two ASC convertors installed in the ASRG EU.

Figure 3 displays a small subset of the results of the testing: two spectra, one for axial vibration and the other for lateral vibration. The lateral spectrum represents the worst-case, largest-acceleration values constructed from four spectra: measured at the accelerometers on the inboard and outboard ASC for each of the two lateral axes. The axial spectrum combines the highest $\mathrm{g}$ level at each frequency from the accelerometers on the inboard and outboard convertors. The spectra have been scaled, since the LM testing was performed at qualification levels. Figure 3 also shows the standard Jet Propulsion Laboratory (JPL) Radioisotope Power Source (RPS) flight acceptance profile that was used as the input at the base of the ASRG EU. As shown, the standard flight acceptance profile used as the input in this testing has an average acceleration of $8.7 \mathrm{grms}$, while the composite lateral spectrum for the ASC in the ASRG EU contains 7.3 grms and the axial spectrum raises the average acceleration to 14.8 grms. 


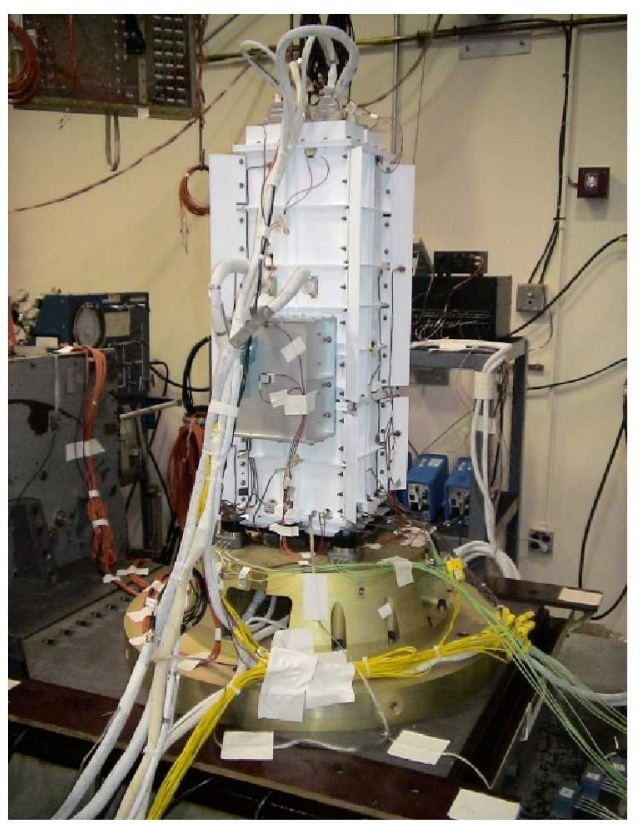

Figure 2.-ASRG EU prepared for lateral axis vibration testing.

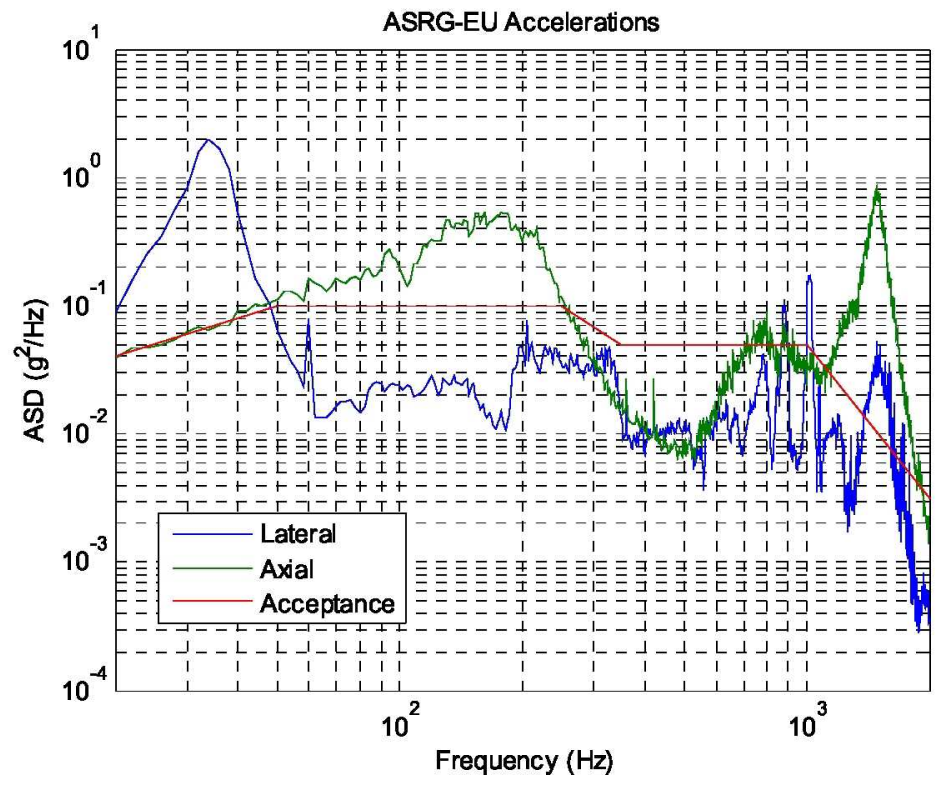

Figure 3.-Vibration spectra from ASRG EU testing.

As Figure 3 shows, the dynamics of the ASRG EU structure significantly impact the vibrational exposure of the convertors in both the axial and lateral directions. One frequency of interest occurs just less than $1500 \mathrm{~Hz}$, where both spectra show a local peak. Above $1500 \mathrm{~Hz}$, the response rolls off rapidly. 


\section{Test Article}

Figure 4 shows one of the ASC-0 convertors used to generate the data for this paper. The ASC-0 convertors represent the first generation of ASC convertors put on extended operation test at GRC. They are configured with Inconel 718 heater heads and therefore operate at a maximum hot-end temperature of $650{ }^{\circ} \mathrm{C}$ and a rejection temperature of $90^{\circ} \mathrm{C}$. The ASC- $0 \# 3$ and $\# 4$ units were hermetically sealed by welding the flange joints, but access to the fill tube remains via an isolation valve. The convertors began operation at GRC in August 2007 and reached over 7,400 hr before being shut down for vibration testing.

Figure 5 depicts ASC- 0 \# mounted in the vibration test fixture. The test fixture supports the convertor through the cold side adapter flange (CSAF) and the pressure vessel flange. The method of supporting the heater represents the principal difference between this mounting scheme and that used in the ASRG EU. In the ASRG EU, as shown in Figure 1, a spring mechanism provides a preload force to hold the heat source against the heater head. In the vibration test fixture for the ASC-0 units, several bolts hold the heater to the heater head.

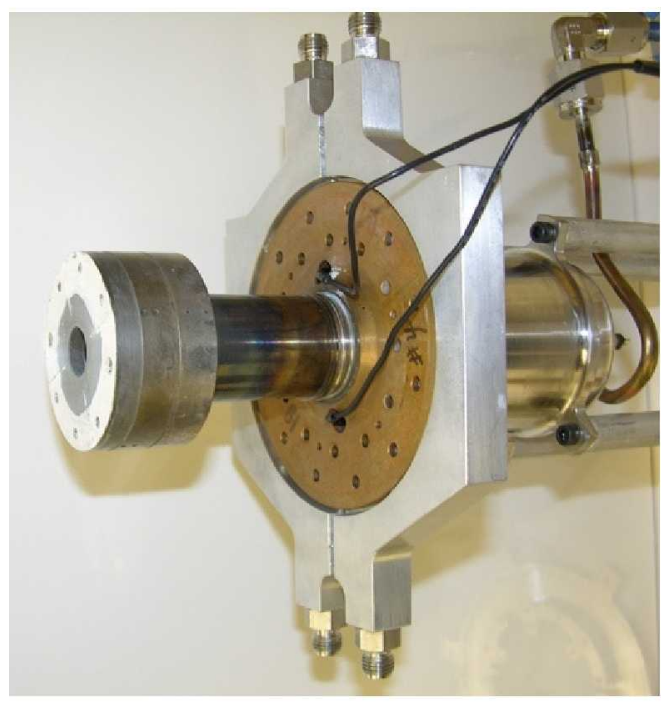

Figure 4.-ASC-0 \#3 convertor.

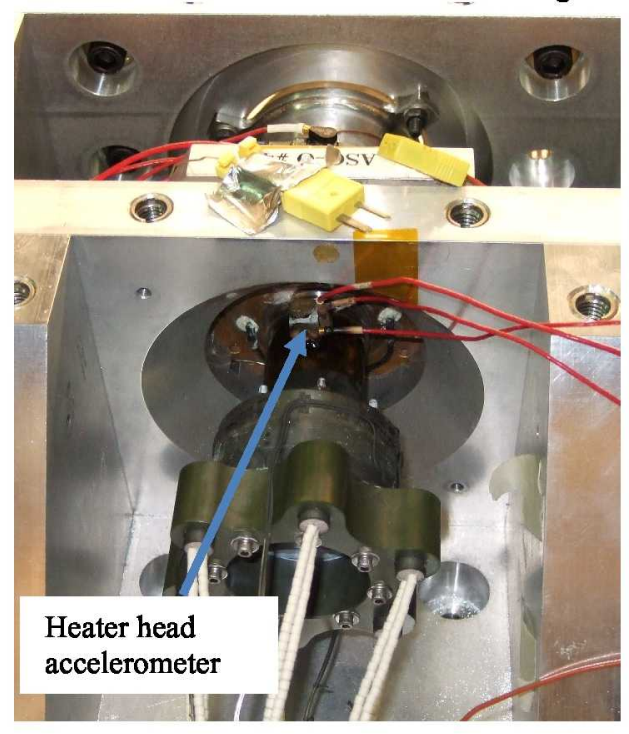

accelerometers

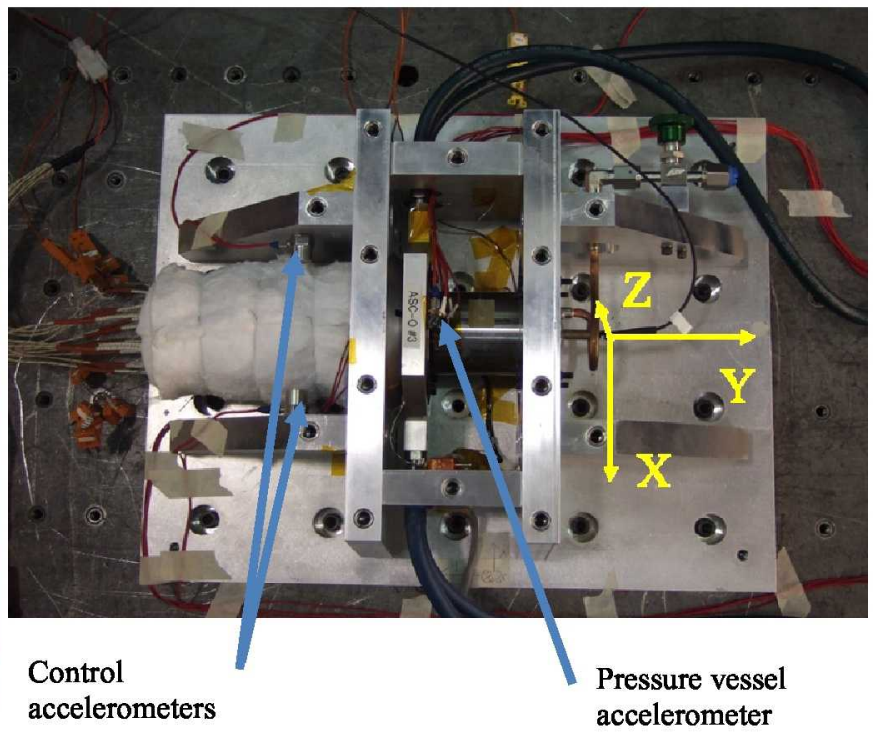

accelerometer

Figure 5.-ASC-0 convertor mounted in vibration test fixture. 
Consequently, the heater head is cantilevered from the fixture, resulting in a different acceleration exposure. Future vibration test fixtures for the Advanced Stirling Convertors will replicate the support system of the ASRG EU more closely.

Each convertor had a triaxial response accelerometer cube mounted to its pressure vessel and heater head as shown in Figure 5. Figure 5 also shows the locations of the two control accelerometers mounted to the test fixture as well as the three axes of the convertor: the $\mathrm{X}$ and $\mathrm{Z}$ axes represent the two lateral directions while the $\mathrm{Y}$ axis is the axial direction. The convertors operated at launch conditions during vibration testing of $625^{\circ} \mathrm{C}$ hot-end temperature, $60{ }^{\circ} \mathrm{C}$ cold-end temperature, and $4.4 \mathrm{~mm}$ piston amplitude.

\section{Test Plan}

The overall test plan for the pair of convertors called for fixture characterization, followed by testing the first unit, ASC-0 \#3, to the standard JPL RPS flight acceptance levels. This test preceded dynamic testing of the ASRG EU so that no acceleration test data at the ASC component level existed - thus the JPL spectrum was used as an approximation of the level and frequency content of the input. Initial testing would reveal any dynamics introduced by the test fixture between the input to the shaker table and the pressure vessel accelerometer in each axis of testing. Based on the results of this initial test, the spectra would be shaped to produce the desired acceleration profile at the pressure vessel accelerometers. ASC- 0 \#4 would then be tested using these modified profiles.

During the vibration test, the SDL data acquisition system recorded 11 accelerometer signals as well as four voltage signals from the convertor under test at $5120 \mathrm{~Hz}$. The four convertor operation signals recorded included the voltage output of the fast linear displacement transducer (FLDT) that measured piston position, the alternator RMS power, the alternator voltage, and the alternator current.

\section{Vibration Test Results}

Frequency characterization testing performed on all three axes of the test fixture prior to the flight acceptance level showed the first natural frequency of the fixture did not fall into the range of interest below $1500 \mathrm{~Hz}$, the frequency point for the peak seen in the ASRG EU axial spectrum. Consequently, the input spectra did not require compensation to account for the fixture dynamics.

Given this result, the test continued with exposure to the standard JPL RPS flight acceptance levels for ASC- 0 \#3 mounted in the test fixture with a level of 8.7 grms. Figure 6 summarizes the results of this test, showing that the response curves at the pressure vessel follow the control input spectra for frequencies under $1000 \mathrm{~Hz}$. Based on this test, it was expected that the input spectra would require some shaping in the 1000 to $2000 \mathrm{~Hz}$ range to match the levels recorded during testing of the ASRG EU.

Based on the results from testing ASC-0 \#3 using the standard JPL RPS profile, spectra were prepared for the axial and lateral directions for testing ASC-0 \#4 in an attempt to replicate the accelerations seen on the pressure vessel accelerometers during ASRG EU vibration testing. During a typical vibration test, the acceleration level steps up by $6 \mathrm{db}$ beginning at the desired level minus $24 \mathrm{db}$. This process reveals the transfer function between the control and output (in this case, pressure vessel) spectra, allowing for adjustment if necessary. In this case, the lateral spectrum (X and Z axis) did not require any adjustment, while the axial spectrum ( $\mathrm{Y}$ axis) required one adjustment.

Figure 7 compares the various spectra associated with the axial and lateral directions of the vibration testing on ASC-0 \#4. These spectra include the standard flight acceptance spectrum, the target spectrum based on ASRG EU testing, the control spectrum, and the spectrum recorded at the pressure vessel accelerometer. 

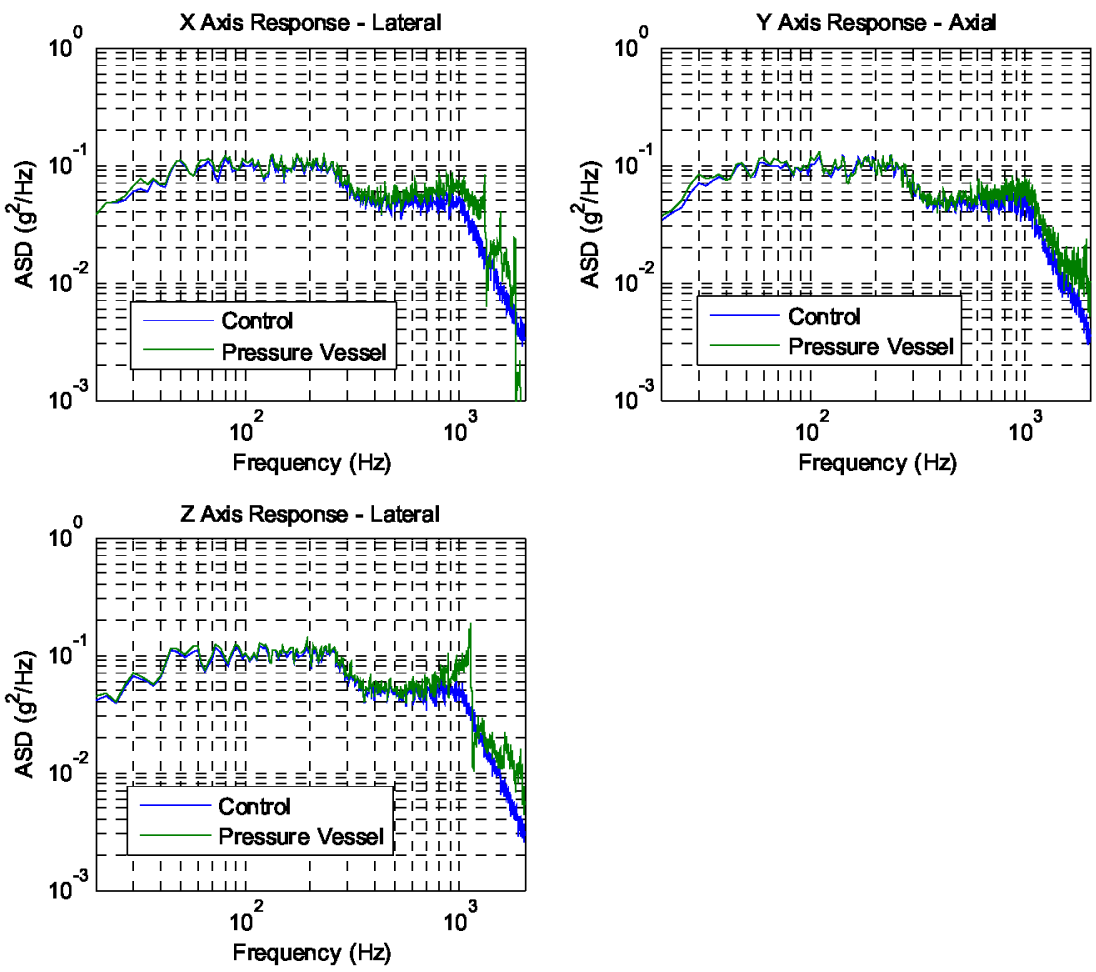

Figure 6.-Pressure vessel accelerometer responses to JPL RPS flight acceptance level vibration.
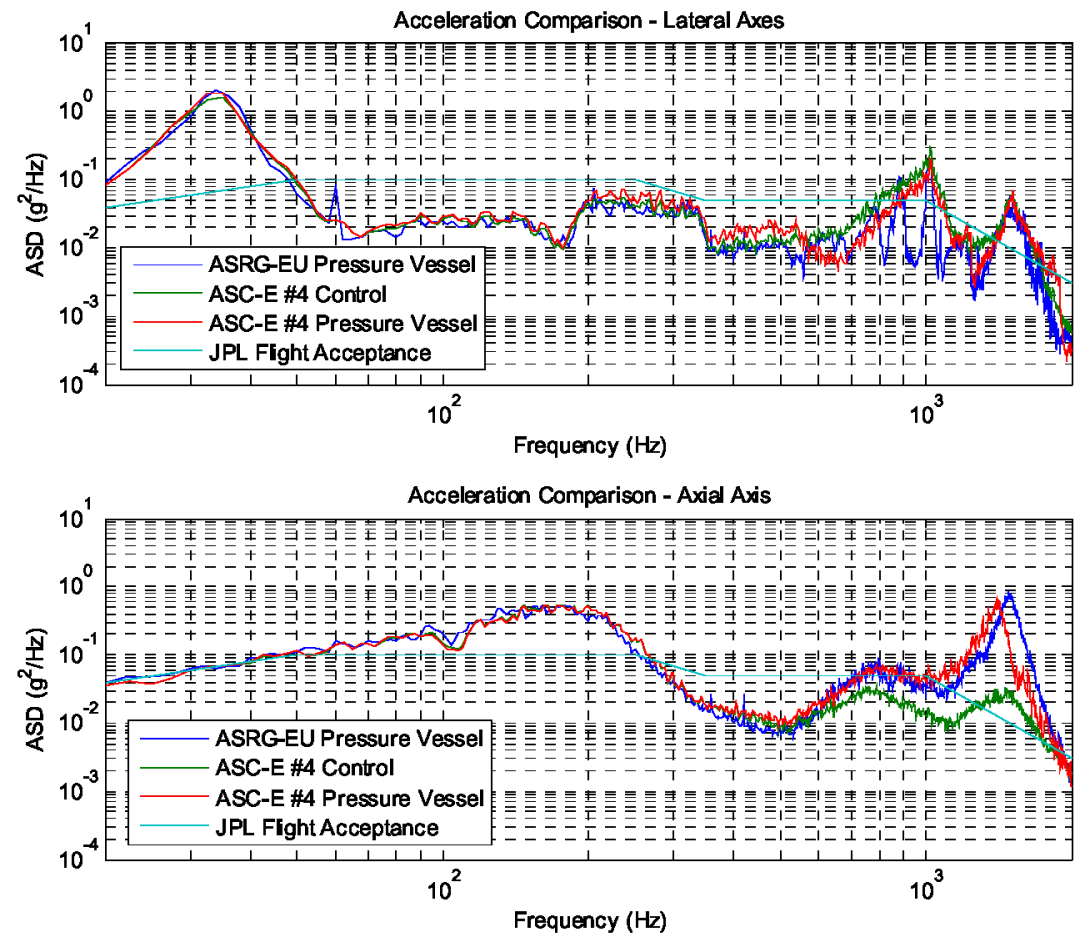

Figure 7.-Comparison of testing spectra for lateral and axial axes. 
In the lateral direction, as Figure 7 shows, the control, pressure vessel, and target spectra matched fairly well. The overall acceleration levels for each response were 8.7 grms for the JPL RPS standard, 8.9 grms for the control, 8.3 grms at the pressure vessel, and 7.3 grms for the ASRG EU. The difference arises primarily due to the three peaks between 700 to $1000 \mathrm{~Hz}$ in the ASRG EU spectrum that the shaped control spectrum does not attempt to duplicate.

In the axial direction, the numbers were 8.7 grms for the JPL RPS standard, 9.7 grms for the control, 13.9 grms at the pressure vessel, and 14.8 grms for the ASRG EU. In this case, the input spectrum required modification. The difference appears most clearly just under $1400 \mathrm{~Hz}$, where the control was reduced to replicate the peak seen in the ASRG EU spectrum.

As stated earlier, one purpose of vibration testing the ASCs is to expose them to accelerations similar to those that a flight convertor would experience. Shaping the spectra as described effectively satisfies this requirement. A second purpose involves verifying that convertors can operate through the launch vibration without sustaining damage by successfully operating at launch conditions during vibration. For this reason, the SDL data acquisition system recorded several variables related to convertor performance during the vibration testing, including piston position, alternator current, alternator voltage, and alternator power. Figure 8 shows the variation of the maximum and minimum piston position recorded during vibration as a function of the acceleration recorded at the pressure vessel accelerometer during testing. While piston position was relatively unaffected under vibration in the lateral direction, position changed by over 15 percent under vibration in-axis to the piston travel. The hard limits for the ASC-0 convertors were of interest. If the piston reached either of these hard stops, it could contact another portion of the convertor, which is outside the design envelope. The test demonstrated that the piston motion only used about half of the available margin when exposed to vibration levels up to 13.9 grms.

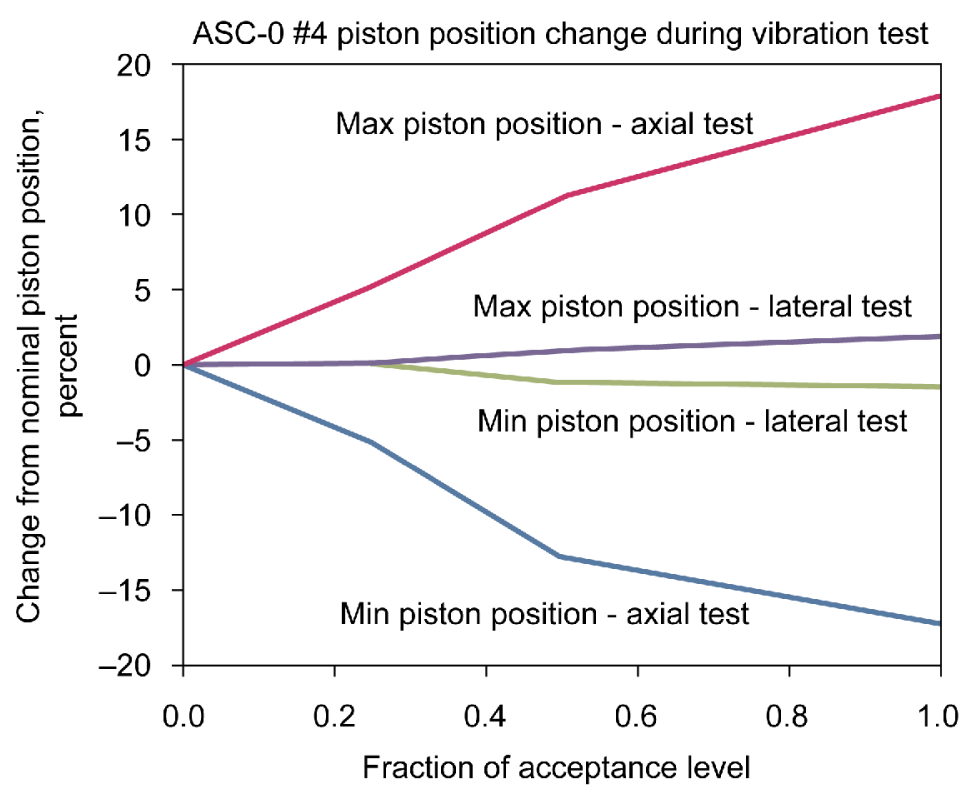

Figure 8.-Variation of maximum and minimum piston position as a function of vibration level. 

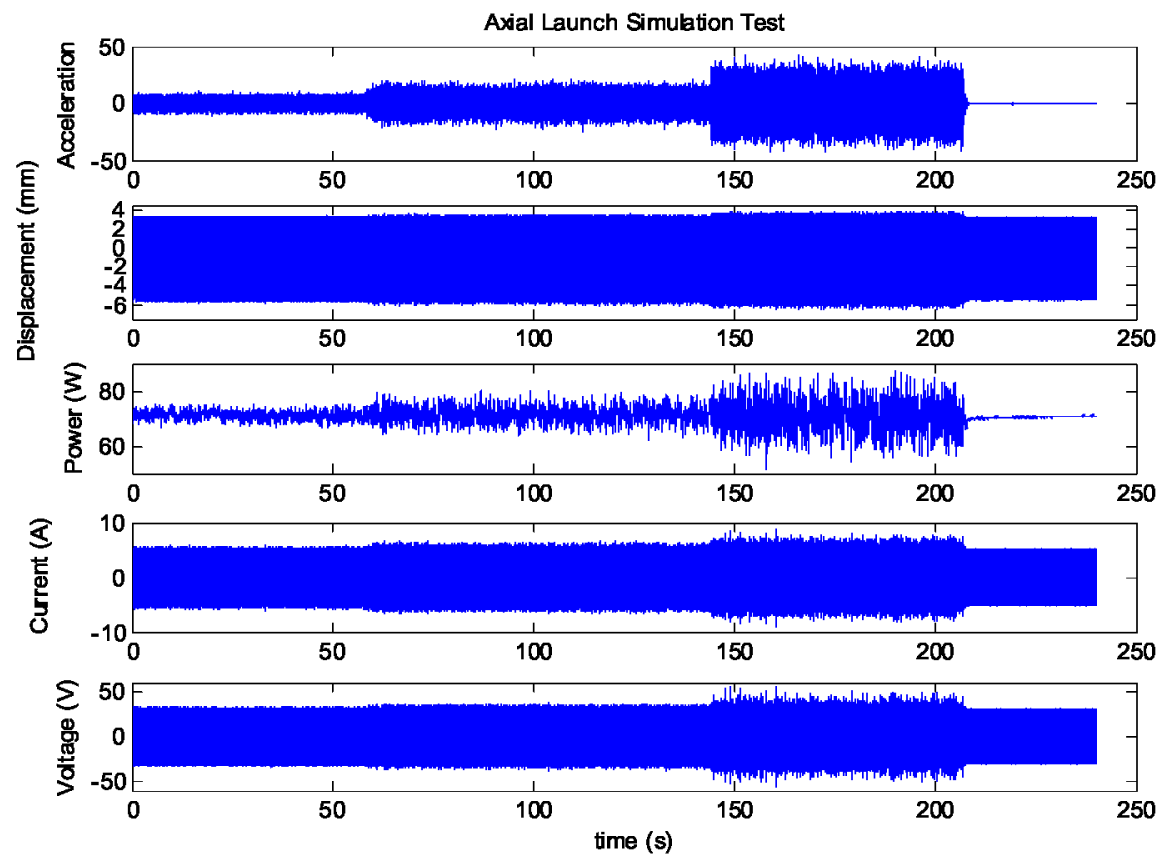

Figure 9.-ASC convertor parameter variation during axial vibration testing up to flight acceptance levels.

Figure 9 shows the variation of several parameters of ASC-0 \#4 during the launch simulation testing in the axial direction for several levels of random vibration input. During the testing, the vibration levels increased in $6 \mathrm{~dB}$ increments, holding at each level for about $1 \mathrm{~min}$. Figure 9 plots the output of the control accelerometer, the piston displacement sensor, and the power, current, and voltage from the ASC linear alternator for vibration levels from -12 to $0 \mathrm{~dB}$, followed by removal of the acceleration at around $210 \mathrm{sec}$. These plots demonstrate that, while vibration does affect the operational parameters of the Stirling convertors, the convertors do continue to operate within acceptable ranges and quickly return to normal once the vibration is removed from the system.

\section{Conclusions}

This paper presents the vibration test approach for current and future Advanced Stirling Convertor units undergoing extended life testing at GRC. This testing aims to replicate the vibration exposure expected for a convertor in a flight application. To improve the accuracy of the vibrational exposure, the test spectra used incorporate the results from vibration testing of the ASRG EU. These spectra, scaled to reduce the acceleration content to flight acceptance levels, provide targets for the signals measured by accelerometers on the convertors. Adjustment of the input spectra produced the desired result of matching the accelerations seen by the pressure vessel accelerometers. Continuous monitoring of several convertor variables showed that, although the external vibration did affect the operation of the convertor, the parameters remained within an acceptable range and the convertor successfully operated throughout the vibration exposure. 


\section{References}

1. Schreiber, Jeffrey G., Thieme, Lanny G., and Wong, Wayne A., "Supporting Technology at GRC to Mitigate Risk as Stirling Power Conversion Transitions to Flight," Proceedings of the 6th International Energy Conversion Engineering Conference, AIAA-2008-5790, Cleveland, OH, 2008.

2. Goodnight, Thomas W., Hughes, William O., and McNelis, M.E., "Dynamics Capability of an Operating Stirling Convertor," Proceedings of the 35th Intersociety Energy Conversion Engineering Conference," AIAA-2000-2839, AIAA, Reston, VA, 2000.

3. Suarez, Vicente J., Goodnight, Thomas W., Hughes, William O., and Samorezov, Sergey, "Vibration Modal Characterization of a Stirling Convertor via Base-Shake Excitation," Proceedings of the Ist International Energy Conversion Engineering Conference, AIAA-2003-6096, AIAA, Reston, VA, 2003.

4. Hill, Dennis, Goodnight, Thomas W., Suarez, Vicente J., Lewandowski, Edward J., Qiu, Songgang, Callahan, John, and Richardson, Rebecca, "Dynamic Characterization of STC Stirling Convertor and Improved Mechanical Integration in SRG110 Power System," Proceedings of the 3rd International Energy Conversion Engineering Conference, AIAA-2005-5746, AIAA, Reston, VA, 2005.

5. Lewandowski, Edward J., Suarez, Vicente J., Goodnight, Thomas W., and Callahan, John, "SRG110 Stirling Generator Dynamic Simulator Vibration Test Results and Analysis Correlation," Proceedings of the 4th International Energy Conversion Engineering Conference, AIAA-2006-4063, AIAA, Reston, VA, 2006. 


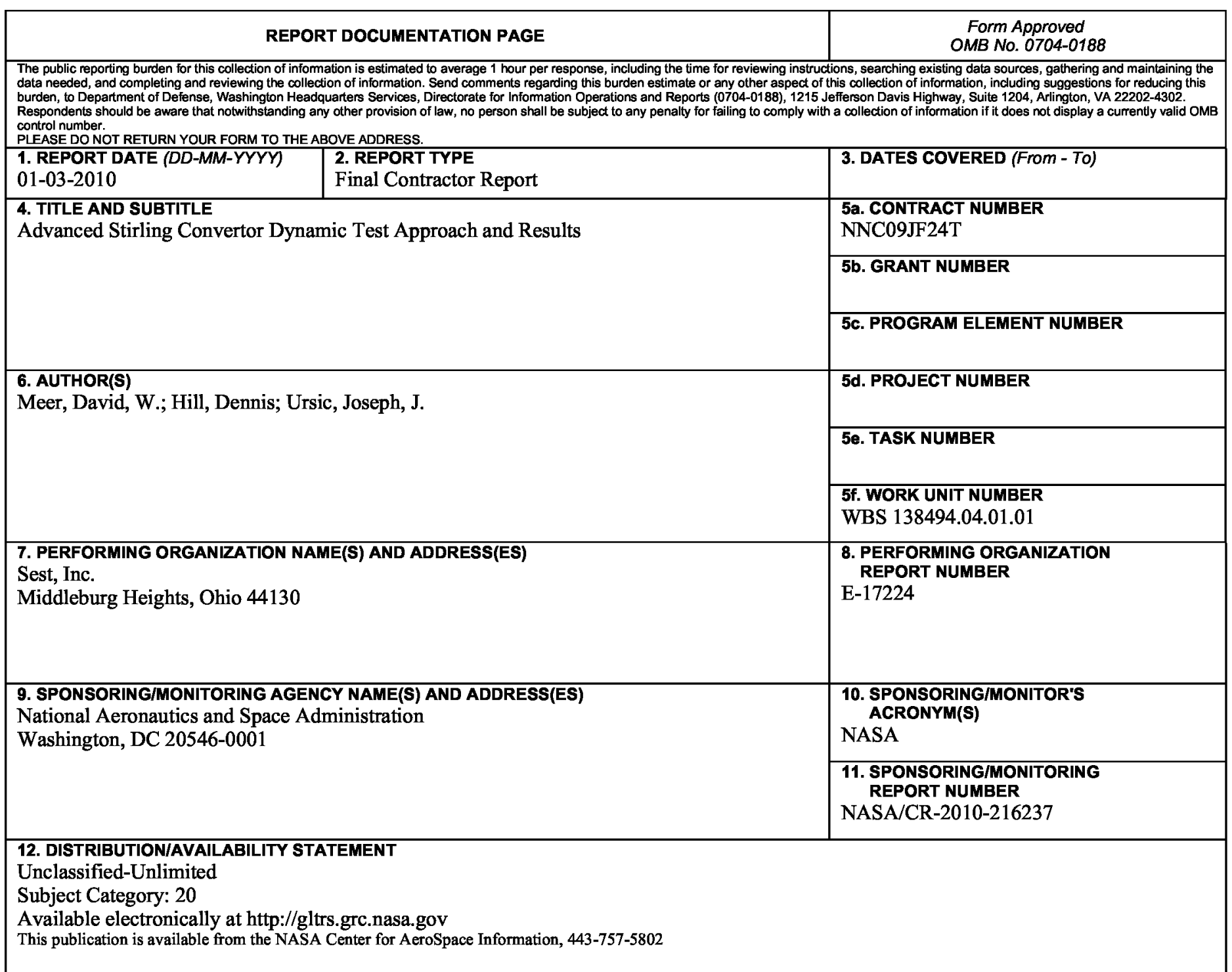

\section{SUPPLEMENTARY NOTES}

\section{ABSTRACT}

The U.S. Department of Energy (DOE), Lockheed Martin Corporation (LM), and NASA Glenn Research Center (GRC) have been developing the Advanced Stirling Radioisotope Generator (ASRG) for use as a power system for space science missions. As part of the extended operation testing of this power system, the Advanced Stirling Convertors (ASC) at NASA GRC undergo a vibration test sequence intended to simulate the vibration history that an ASC would experience when used in an ASRG for a space mission. This sequence includes testing at workmanship and flight acceptance levels interspersed with periods of extended operation to simulate prefueling and post fueling. The final step in the test sequence utilizes additional testing at flight acceptance levels to simulate launch. To better replicate the acceleration profile seen by an ASC incorporated into an ASRG, the input spectra used in testing the convertors was modified based on dynamic testing of the ASRG Engineering Unit (ASRG EU) at LM. This paper outlines the overall test approach, summarizes the test results from the ASRG $\mathrm{EU}$, describes the incorporation of those results into the test approach, and presents the results of applying the test approach to the ASC-1 \#3 and \#4 convertors. The test results include data from several accelerometers mounted on the convertors as well as the piston position and output power variables.

15. SUBJECT TERMS

Advanced Stirling radioisotope generator; Advanced Stirling convertors; Power systems; Vibration testing

\begin{tabular}{|c|c|c|c|c|c|}
\hline \multicolumn{3}{|c|}{ 16. SECURITY CLASSIFICATION OF: } & \multirow{2}{*}{$\begin{array}{l}\text { 17. LIMITATION OF } \\
\text { ABSTRACT } \\
\text { UU }\end{array}$} & \multirow{2}{*}{$\begin{array}{l}\text { 18. NUMBER } \\
\text { OF } \\
\text { PAGES } \\
16\end{array}$} & \multirow{2}{*}{$\begin{array}{l}\text { 19a. NAME OF RESPONSIBLE PERSON } \\
\text { STI Help Desk (email:help@sti.nasa.gov) } \\
\text { 19b. TELEPHONE NUMBER (include area code) } \\
\text { 443-757-5802 }\end{array}$} \\
\hline $\begin{array}{l}\text { a. REPORT } \\
\text { U }\end{array}$ & $\begin{array}{l}\text { b. ABSTRACT } \\
\text { U }\end{array}$ & $\begin{array}{l}\text { c. THIS } \\
\text { PAGE } \\
\text { U }\end{array}$ & & & \\
\hline
\end{tabular}



